\title{
Phacoemulsification after Trabeculectomy in Uveitis Associated with Vogt-Koyanagi-Harada Disease: Intermediate-Term Visual Outcome, IOP Control and Trabeculectomy Survival
}

Faisal A. Almobarak ( $\nabla$ falmobarak@ksu.edu.sa )

King Saud University https://orcid.org/0000-0003-3504-2828

Ali Alharbi

King Abdullah Medical City

Ibrahim Aljadaan

King Khaled Eye Specialist Hospital

Hasan Aldhibi

King Khaled Eye Specialist Hospital

\section{Research Article}

Keywords: Glaucoma, Uveitis, trabeculectomy, cataract, Vogt-Koyanagi-Harada disease

Posted Date: April 6th, 2021

DOl: https://doi.org/10.21203/rs.3.rs-372272/v1

License: (c) (1) This work is licensed under a Creative Commons Attribution 4.0 International License.

Read Full License 


\section{Abstract}

\section{Purpose}

To evaluate the visual outcome, intraocular pressure control and survival of trabeculectomy after phacoemulsification in eyes with prior trabeculectomy in uveitis associated with Vogt-Koyanagi-Harada disease $(\mathrm{VKH})$.

Design

Retrospective comparative study.

Methods

Eyes with uveitic glaucoma associated with VKH who underwent mitomycin C (MMC)-enhanced trabeculectomy were included. Eyes were divided into two groups: the first study group included eyes that later underwent cataract surgery in the form of phacoemulsification, and the second control group included eyes that did not have cataract surgery. The main outcome measures were changes in the visual acuity, intraocular pressure (IOP), the number of antiglaucoma medications, IOP control and trabeculectomy survival.

Results

There were no significant differences in the final visual acuity $(0.78( \pm 0.9)$ and $0.92( \pm 1.1), p=0.80))$ nor IOP $(14.21 \mathrm{mmHg}( \pm 5.8)$ and $12.16 \mathrm{mmHg}( \pm 6.1), p=0.29)$, but there was a difference in the antiglaucoma medications $(1.58( \pm 1.5)$ and $0.53( \pm 1.0), p=0.02)$ between the study and control group, respectively. There was no difference in the overall trabeculectomy survival ( $p=0.381$, Log Rank), but more eyes in the study group converted to qualified success after phacoemulsification and required more medications to control the IOP.

\section{Conclusion}

Phacoemulsification after trabeculectomy seems to be a safe procedure in eyes with combined vision threatening complications of $\mathrm{VKH}$, although the visual improvement was limited. Nevertheless, more medications were required to control the IOP, thereby affecting IOP control; but such medication did not affect trabeculectomy survival. Therefore, patient counselling before surgery is essential.

\section{Introduction}

Vogt-Koyanagi-Harada disease (VKH) is a T-cell mediated autoimmune disease against antigen or antigens associated with melanocytes which commonly affects pigmented races such as Asians, Native Americans, Hispanics, Indians and Middle easterners. ${ }^{1-2}$ The acute disease phase is characterized by bilateral granulomatous panuveitis and exudative retinal detachment, while the chronic phase includes 
recurrent granulomatous anterior uveitis with typical sunset glow fundus and chorioretinal atrophy. ${ }^{3-4}$ Cataract, glaucoma, subretinal neovascular membranes and fibrosis are vision-threatening complications recognized to occur mostly in the chronic recurrent phase and associated with poor visual outcome..$^{5-8}$ Cataract is the most common complication of VKH accounting for $25 \%$ of visual loss and has a prevalence of $40 \%$. In addition, cataract and glaucoma surgeries are the most common surgeries carried out for patients with $\mathrm{VKH} .{ }^{2,7-9}$

Several studies have reported favorable visual outcome of cataract surgery in VKH patients. Such an outcome can be achieved by controlling the intraocular inflammation in the absence of other visionthreatening complications of $\mathrm{VKH} .{ }^{9-11}$ However, such an outcome is unknown in patients who had combined glaucoma and cataract. Given that trabeculectomy is one of the commonly performed surgeries needed to control glaucoma in VKH patients and an important cataractogenic factor in uveitic glaucoma, 7,8,12,13 we were interested to evaluate the visual outcome, intraocular pressure (IOP) control and trabeculectomy survival after phacoemulsification in patients with previous trabeculectomy.

\section{Materials And Methods}

\section{Patients}

We reviewed medical records of patients with uveitic glaucoma associated with VKH who underwent MMC-enhanced trabeculectomy at King Khaled Eye Specialist Hospital, Riyadh, Saudi Arabia. The diagnosis of VKH disease was based on the Revised International Diagnostic Criteria. ${ }^{14}$ The inclusion criteria were (i) controlled IOP of $<21 \mathrm{mmHg}$ with or without antiglaucoma medications, (ii) phakic eyes, (iii) no previous history of a pressure-lowering procedure other than a single MMC-enhanced trabeculectomy and (iv) a minimum follow-up time of one year. We identified 45 eyes of 23 patients out of which 19 eyes underwent phacoemulsification with intraocular lens implantation later on. Eyes were divided into 2 groups: the study group included eyes that underwent phacoemulsification after trabeculectomy and the control group included eyes that underwent only trabeculectomy surgery. We followed the same methods described by Almobarak et al. ${ }^{15}$ The control pairs were matched according to age, gender, trabeculectomy and phacoemulsification (study eyes)/admittance to the study (control eyes) time, best corrected visual acuity (BCVA), IOP and number of glaucoma medications. To match the studycontrol pairs with respect to trabeculectomy and phacoemulsification (study eyes)/admittance to the study time (control eyes), the time interval between trabeculectomy and phacoemulsification and between phacoemulsification and the final follow-up was calculated for the study group. For the control group, the study entry time was determined as the best matching time for that control eye with study eye considering the time between trabeculectomy and phacoemulsification of the study eye. Time interval between trabeculectomy and study entry, and then between study entry and final follow-up was determined. These times periods were then utilized to match the control and study eyes. Ultimately, 19 study eyes and 19 control eyes were included in the study. The study was approved by the Ethics Review Board of King Khaled Eye Specialist Hospital, part of a retrospective study on uveitic glaucoma. All 
procedures adhered to the tenets of the declaration of Helsinki, and all patients gave written informed consent.

\section{Surgical Technique}

All patients were evaluated by uveitis specialist before surgery. Phacoemulsification was performed by experienced surgeons credentialed for the procedure. The temporal corneal incision was performed to avoid the filtering bleb superiorly. Any posterior synechiae were released with viscoelastic material or a cyclodialysis spatula before phacoemulsification. Iris retractors were employed when needed. A foldable intraocular lens (IOL) was implanted in the bag, and the wound was hydrated or closed with 10-0 nylon sutures. Finally, subconjunctival injections of antibiotics and steroids were administered. The patients were checked postoperatively depending on the stability of their condition. After the surgery, all of the patients were treated with topical antibiotics and prednisolone drops; the dosage was gradually adjusted and tapered to the preoperative maintenance dosage by the uveitis specialist. Systemic immunosuppressive agents such as steroids were administered to achieve the optimal control of the inflammation. Postoperative monitoring was carried out by both the glaucoma and uveitis specialists.

\section{Data Analysis}

Data were collected whenever available and applicable for the following variables: age, gender, best corrected visual acuity (BCVA) converted into logarithm of minimal angle of resolution (logMAR) format, IOP, number of antiglaucoma medications and the need for subsequent pressure-lowering procedures to control the IOP after phacoemulsification. Good VA was defined as a BCVA of 20/40 or better, while poor VA was defined as a BCVA worse than 20/40. Grading of the anterior chamber cells was done following the standardization of uveitis nomenclature scheme. ${ }^{16}$ Quiescence was defined as occasional cells or less, and recurrence of inflammation as a two-step increase to at least +2 cells. The standardization of uveitis nomenclature for recurrence was followed and attributed to VKH if it occurred after 3 months from phacoemulsification. ${ }^{11}$ All surgeries were performed after having a quiescence of at least 3 months. We evaluated variables between the 2 groups using the unpaired Student t-test, Mann-Whitney U test or Chisquare test, and within groups using the Wilcoxon pair test and paired Student t-test. We considered trabeculectomy as (i) complete success if the IOP was between 6 and $21 \mathrm{mmHg}$ without antiglaucoma medications; (ii) qualified success if the IOP was between 6 and $21 \mathrm{mmHg}$ with antiglaucoma medications; (iii) failure if the IOP was more than $21 \mathrm{mmHg}$ on two visits despite maximum tolerated antiglaucoma medications or if an additional glaucoma procedure was needed to control the IOP. The cumulative probabilities of overall success, presented as percentage \pm standard error (SE), were determined by Kaplan-Meier life table analysis for both groups and compared using the Mantel-Cox logrank test. We presented variables as mean and standard deviation (SD), and considered $p$ values of less than 0.05 to indicate statistical significance. Statistical analysis was carried out using SPSS version 23 (SPSS Inc., Chicago, IL).

\section{Results}


Thirty-eight eyes of 22 patients, 10 males (45.5\%) and 12 (54.5\%) females, were included in this study. Ten eyes of 5 patients were included in each group. In the study group, 19 eyes underwent uneventful phacoemulsification with placement of a foldable IOL in the bag, with or without synecholysis. For the study eyes, the mean time between trabeculectomy and phacoemulsification was 33.21 months $( \pm 33.3)$, and the mean follow-up time was 45.75 months $( \pm 36.4)$. In the control group, the mean time between trabeculectomy and study entry was 35.79 months $( \pm 36.6)$, and the mean follow-up time was 50.33 months $( \pm 38.9)$; these differences between the 2 groups were not statistically significant $(p=0.82$ and 0.71 , respectively, Mann-Whitney $U$ test). The mean ages of the patients in the study and control groups were $29.21( \pm 9.1)$ and 33.61 years $( \pm 11.0)$, respectively $(p=0.19$, Mann-Whitney $U$ test) (Table 1$)$. There were no significant differences in the mean preoperative LogMAR, IOP nor number of antiglaucoma medications between the study and control groups ( $p=0.90,0.14$ and 0.27 , respectively). On the last follow-up, there were no differences in the mean LogMAR $(0.78( \pm 0.9)$ and $0.92( \pm 1.1), p=0.8)$ nor IOP $(14.21 \mathrm{mmHg}( \pm 5.8)$ and $12.16 \mathrm{mmHg}( \pm 6.1), p=0.29)$, but there was a difference in the antiglaucoma medications (1.58 medications $( \pm 1.5)$ and 0.53 medications $( \pm 1.0), p=0.02)$ in the study and control groups, respectively. During the whole follow-up period, more eyes in the study group had good VA (20/40 or better) after phacoemulsification than the control group, although not statistically significant. On the last visit, the VA improved by 2 lines or more in 10 eyes (52.6\%) in the study group, one eye (5.3\%) improved by one line, one eye had the same VA (5.3\%) and 7 eyes $(36.8 \%)$ had worse VA. Factors contributing to such deterioration in VA include pre-existing advance glaucomatous damage, macular edema and subretinal neovascular membranes and fibrosis. In the presence of cataract in uveitis with vision threatening complications, the goal of surgical intervention is not only visual rehabilitation, but also to have a better visualization of the retina and optic nerve and monitor progression. When the 2 groups were compared, there were no differences in IOP nor logMAR throughout the follow-up period. Nevertheless, there was a difference in the mean number of antiglaucoma medications on all postoperative visits except at 3 and 12 months. The intragroup analysis demonstrated significant differences in the mean number of antiglaucoma medications in the study group but none in the control group (Table 2). Two eyes in the control group developed recurrence of anterior chamber inflammation but none in the study group. 
Table 1

Demographics and ocular history*

\begin{tabular}{|c|c|c|c|}
\hline Variable & $\begin{array}{l}\text { Study } \\
\text { Group } \\
(n=19)\end{array}$ & $\begin{array}{l}\text { Control } \\
\text { Group } \\
(n=19)\end{array}$ & $\begin{array}{l}P \text { - } \\
\text { value }\end{array}$ \\
\hline Age, years & $\begin{array}{l}29.21( \pm \\
9.1)\end{array}$ & $\begin{array}{l}33.61( \pm \\
11.0)\end{array}$ & 0.19 \\
\hline Gender** & $2(20.0 \%)$ & $8(80.0 \%)$ & \multirow[t]{3}{*}{0.09} \\
\hline Male (10) & $7(58.3 \%)$ & $5(41.7 \%)$ & \\
\hline \multicolumn{3}{|l|}{ Female (12) } & \\
\hline Pre-Trabeculectomy: & $0.68( \pm 0.5)$ & $0.86( \pm 0.9)$ & 0.10 \\
\hline LogMAR & $\begin{array}{l}40.05( \pm \\
9.1)\end{array}$ & $\begin{array}{l}39.16( \pm \\
8.4)\end{array}$ & 0.76 \\
\hline Mean IOP before Trabeculectomy, mmHg & \multirow{2}{*}{$3.95( \pm 0.6)$} & \multirow{2}{*}{$3.74( \pm 0.7)$} & \multirow[t]{2}{*}{0.35} \\
\hline $\begin{array}{l}\text { Mean number of antiglaucoma medications before } \\
\text { Trabeculectomy }\end{array}$ & & & \\
\hline Time to cataract surgery/study entry, months & $\begin{array}{l}33.21( \pm \\
33.3)\end{array}$ & $\begin{array}{l}35.79( \pm \\
36.6)\end{array}$ & 0.82 \\
\hline Follow-up, months & $\begin{array}{l}45.75( \pm \\
36.4)\end{array}$ & $\begin{array}{l}50.33( \pm \\
38.9)\end{array}$ & 0.71 \\
\hline \multicolumn{4}{|c|}{ *Data are presented as mean $( \pm S D)$ and frequencies $(\%)$. Numbers are per eyes. } \\
\hline \multicolumn{4}{|l|}{$\star \star$ Numbers are per patients. } \\
\hline P-values were calculated using Student t-test, Mann- & st and $\mathrm{Ch}$ & are test. & \\
\hline
\end{tabular}


Table 2

IOP, antiglaucoma medications, LogMAR and changes in BCVA*

\begin{tabular}{|c|c|c|c|}
\hline Variable & $\begin{array}{l}\text { Study Group } \\
(n=19)\end{array}$ & $\begin{array}{l}\text { Control group } \\
(n=19)\end{array}$ & P-value \\
\hline Baseline & $14.05( \pm 4.3)$ & $12.16( \pm 3.4)$ & 0.14 \\
\hline IOP, mmHg & $0.42( \pm 0.7)$ & $0.46( \pm 0.5)$ & 0.27 \\
\hline No. of medications & $0.74( \pm 0.6)$ & $0.71( \pm 0.6)$ & 0.90 \\
\hline LogMAR & $4(21.1 \%)$ & $4(21.1 \%)$ & 0.90 \\
\hline BCVA $20 / 40$ or better & $15(78.9 \%)$ & $15(78.9 \%)$ & \\
\hline \multicolumn{4}{|l|}{ BCVA worse than $20 / 40$} \\
\hline 3 Months postoperative & $14.73( \pm 4.3)$ & $12.46( \pm 8.9)$ & 0.92 \\
\hline IOP, mmHg & $(p=0.18)$ & $(p=0.31)$ & 0.76 \\
\hline$(P \text {-value })^{\star \star}$ & $0.53( \pm 0.6)$ & $0.63( \pm 1.0)$ & 0.55 \\
\hline No. of medications & $(p=0.30)$ & $(p=0.11)$ & 0.16 \\
\hline$(\text { P-value })^{\star \star}$ & $0.68( \pm 0.2)$ & $0.84( \pm 1.0)$ & \\
\hline LogMAR & $(p=0.29)$ & $(p=0.70)$ & \\
\hline$(P \text {-value })^{\star \star}$ & $9(47.4 \%)$ & $5(26.3 \%)$ & \\
\hline BCVA $20 / 40$ or better & $10(52.6 \%)$ & $14(73.7 \%)$ & \\
\hline BCVA worse than $20 / 40$ & & & \\
\hline
\end{tabular}

*Data are presented as mean $( \pm S D)$.

${ }^{* *}$ Compared with baseline value in the group.

P-values are calculated using Student t-test, Mann-Whitney U test, Wilcoxon test and Chi-square test. 


\begin{tabular}{|c|c|c|c|}
\hline Variable & $\begin{array}{l}\text { Study Group } \\
(n=19)\end{array}$ & $\begin{array}{l}\text { Control group } \\
(n=19)\end{array}$ & P-value \\
\hline 12 Months postoperative & $17.00( \pm 6.8)$ & $13.00( \pm 6.1)$ & 0.25 \\
\hline IOP, mmHg & $(p=0.36)$ & $(p=0.27)$ & 0.16 \\
\hline$(P \text {-value })^{\star \star}$ & $1.08( \pm 1.6)$ & $0.62( \pm 0.9)$ & 0.81 \\
\hline No. of medications & $(p=0.02)$ & $(p=0.21)$ & 0.29 \\
\hline$(P \text {-value })^{\star \star}$ & $0.78( \pm 0.6)$ & $0.85( \pm 0.8)$ & \\
\hline LogMAR & $(p=0.42)$ & $(p=0.32)$ & \\
\hline$(P \text {-value })^{\star \star}$ & $10(52.6 \%)$ & $5(26.3 \%)$ & \\
\hline BCVA $20 / 40$ or better & $9(47.4 \%)$ & $14(73.7 \%)$ & \\
\hline \multicolumn{4}{|l|}{ BCVA worse than $20 / 40$} \\
\hline 24 Months postoperative & $13.71( \pm 3.6)$ & $12.00( \pm 5.8)$ & 0.42 \\
\hline IOP, mmHg & $(p=0.35)$ & $(p=0.91)$ & 0.04 \\
\hline (P-value) $)^{\star \star}$ & $1.00( \pm 1.2)$ & $0.52( \pm 0.7)$ & 0.69 \\
\hline No. of medications & $(p=0.04)$ & $(p=0.54)$ & 0.21 \\
\hline$(P \text {-value })^{\star \star}$ & $0.72( \pm 0.8)$ & $0.77( \pm 0.9)$ & \\
\hline LogMAR & $(p=0.39)$ & $(p=0.40)$ & \\
\hline$(P \text {-value })^{\star \star}$ & $10(52.6 \%)$ & $6(31.6 \%)$ & \\
\hline BCVA $20 / 40$ or better & $9(47.4 \%)$ & $13(68.4 \%)$ & \\
\hline BCVA worse than $20 / 40$ & & & \\
\hline
\end{tabular}

*Data are presented as mean $( \pm S D)$.

**Compared with baseline value in the group.

P-values are calculated using Student t-test, Mann-Whitney $U$ test, Wilcoxon test and Chi-square test. 


\begin{tabular}{|c|c|c|c|}
\hline Variable & $\begin{array}{l}\text { Study Group } \\
(n=19)\end{array}$ & $\begin{array}{l}\text { Control group } \\
(n=19)\end{array}$ & P-value \\
\hline 36 Months postoperative & $14.80( \pm 1.3)$ & $13.50( \pm 7.5)$ & 0.71 \\
\hline IOP, mmHg & $(p=0.88)$ & $(p=0.75)$ & 0.02 \\
\hline$(P \text {-value })^{\star \star}$ & $1.00( \pm 1.7)$ & $0.50( \pm 0.8)$ & 0.51 \\
\hline No. of medications & $(p=0.03)$ & $(p=0.74)$ & 0.30 \\
\hline$(P \text {-value })^{\star \star}$ & $0.79( \pm 0.7)$ & $0.81( \pm 0.8)$ & \\
\hline LogMAR & $(p=0.47)$ & $(p=0.29)$ & \\
\hline$(P \text {-value })^{\star \star}$ & $9(47.4 \%)$ & $6(31.6 \%)$ & \\
\hline BCVA $20 / 40$ or better & $10(52.6 \%)$ & $13(68.4 \%)$ & \\
\hline \multicolumn{4}{|l|}{ BCVA worse than $20 / 40$} \\
\hline Last visit & $14.21( \pm 5.8)$ & $12.61( \pm 6.1)$ & 0.29 \\
\hline IOP, mmHg & $(p=0.92)$ & $(p=0.91)$ & 0.02 \\
\hline$(P \text {-value })^{\star \star}$ & $1.58( \pm 1.5)$ & $0.53( \pm 1.0)$ & 0.69 \\
\hline No. of medications & $(p=0.02)$ & $(p=0.17)$ & 0.37 \\
\hline$(P \text {-value })^{\star \star}$ & $0.78( \pm 0.9)$ & $0.92( \pm 1.0)$ & \\
\hline LogMAR & $(p=0.84)$ & $(p=0.59)$ & \\
\hline$(P \text {-value })^{\star \star}$ & $9(47.4 \%)$ & $7(36.8 \%)$ & \\
\hline BCVA $20 / 40$ or better & $10(52.6 \%)$ & $12(63.2 \%)$ & \\
\hline \multicolumn{4}{|l|}{ BCVA worse than $20 / 40$} \\
\hline \multicolumn{4}{|c|}{${ }^{*}$ Data are presented as mean $( \pm S D)$} \\
\hline \multicolumn{4}{|c|}{$\star \star$ Compared with baseline value in the group. } \\
\hline P-values are calculated us & est, Mann-Wh & st, Wilcoxon te & ii-squar \\
\hline
\end{tabular}

The cumulative probabilities of overall success of the trabeculectomy for the study group were $68.4 \%$ ( \pm $10.7 \%), 47.4 \%( \pm 11.5 \%)$ and $31.6 \%( \pm 10.7 \%)$ compared with $78.9 \%( \pm 9.4 \%), 57.9 \%( \pm 11.3 \%)$ and $31.6 \%$ $( \pm 10.7 \%)$ in the control group at 12,24 and 36 months after surgery, respectively; there was no significant difference in the trabeculectomy survival rate between the 2 groups $(p=0.381$, Log Rank) (Fig. 1). The absolute success rate decreased from $78.9 \%$ and $84.2-31.6 \%$ and $52.6 \%$ on the last follow-up in study and control groups, respectively; whereas the qualified success rate increased from $21.1-36.8 \%$ in the study group but did not change in control group (15.8\%). At the final follow-up, 7 eyes (36.8\%) in the study group and 9 control eyes (47.4\%) maintained their success status (either absolute or qualified 
success) (Table 3). The trabeculectomy failed in 6 eyes (31.6\%) in each group:3 eyes in the study group needed additional glaucoma procedures to control the IOP, compared with 4 eyes in the control group (Table 4).

Table 3

Success status and antiglaucoma medications in study and control groups*

\begin{tabular}{|c|c|c|c|c|c|c|}
\hline & \multicolumn{3}{|l|}{ Baseline } & \multicolumn{3}{|c|}{ Last follow-up } \\
\hline & $\begin{array}{l}\text { Study } \\
\text { Group }\end{array}$ & $\begin{array}{l}\text { Control } \\
\text { Group }\end{array}$ & $\begin{array}{l}\text { P- } \\
\text { value }\end{array}$ & $\begin{array}{l}\text { Study } \\
\text { Group }\end{array}$ & $\begin{array}{l}\text { Control } \\
\text { Group }\end{array}$ & $\begin{array}{l}\text { P- } \\
\text { value** }\end{array}$ \\
\hline \multirow{4}{*}{$\begin{array}{l}\text { Success status } \\
\text { Absolute } \\
\text { success } \\
\text { (maintain } \\
\text { status) } \\
\text { (failed) }\end{array}$} & 15 (78.9\%) & $16(84.2 \%)$ & \multirow[t]{9}{*}{0.50} & \multirow[t]{4}{*}{$6(31.6 \%)$} & \multirow[t]{4}{*}{10 (52.6\%) } & \multirow[t]{9}{*}{0.28} \\
\hline & $(5 / 15)$ & $(8 / 16)$ & & & & \\
\hline & $(5 / 15)$ & $(6 / 16)$ & & & & \\
\hline & & & & & & \\
\hline \multirow{4}{*}{$\begin{array}{l}\text { Qualified } \\
\text { success } \\
\text { (maintain } \\
\text { status) } \\
\text { (failed) }\end{array}$} & $4(21.1 \%)$ & $3(15.8 \%)$ & & \multirow[t]{4}{*}{$7(36.8 \%)$} & \multirow[t]{4}{*}{$3(15.8 \%)$} & \\
\hline & $(2 / 4)$ & $(1 / 3)$ & & & & \\
\hline & $(1 / 4)$ & Zero & & & & \\
\hline & & & & & & \\
\hline Failure & - & - & & $6(31.6 \%)$ & $6(31.6 \%)$ & \\
\hline \multicolumn{7}{|l|}{ Medications } \\
\hline One or None & 17 (89.5\%) & 19 (100\%) & 0.24 & $10(52.6 \%)$ & 15 (78.9\%) & 0.09 \\
\hline Two or more & $2(10.5 \%)$ & Zero & & 9 (47.4\%) & $4(21.1 \%)$ & \\
\hline
\end{tabular}


Table 4

Eyes needed repeat glaucoma surgery*

\begin{tabular}{|lll|}
\hline & $\begin{array}{l}\text { Study Group } \\
(\mathbf{n = 1 9 )}\end{array}$ & $\begin{array}{l}\text { Control Group } \\
\mathbf{( n = 1 9 )}\end{array}$ \\
\hline First repeat surgery & $3 / 19(15.8 \%)$ & $4 / 19(21.1 \%)$ \\
Trabeculectomy + MMC & 2 & 3 \\
Tube surgery & 1 & 0 \\
Cyclophotocoagulation & 0 & 1 \\
\hline Second repeat surgery & $3 / 19(15.8 \%)$ & $1 / 19(5.3 \%)$ \\
Trabeculectomy + MMC & 0 & Zero \\
Tube surgery & 3 & 1 \\
Cyclophotocoagulation & 0 & 0 \\
Third repeat surgery & None & $1 / 19(5.3 \%)$ \\
Trabeculectomy + MMC & - & 0 \\
Tube surgery & - & 0 \\
Cyclophotocoagulation & - & 1 \\
\hline
\end{tabular}

\section{Discussion}

VKH is one of the most common uveitis entities in Saudi Arabia affecting mostly young adults. Glaucoma and cataract are among the most common complications in such entity. ${ }^{17,18}$ Several studies have reported a high frequency $(23.1-51.6 \%)$ of cataract development and progression in uveitic glaucoma eyes after trabeculectomy which eventually required cataract surgery. Cataract surgery in trabeculectomized eyes with uveitis is challenging as a result of the high risk of postoperative inflammation and loss of IOP control. Nevertheless, decreased perioperative and long-term intraocular inflammation and improved microsurgical techniques have all resulted in better outcomes. ${ }^{19}$

We have previously reported favorable outcome of phacoemulsifications after trabeculectomy in uveitis. ${ }^{15}$ However, the outcome in a major uveitis entity such as VKH is not well known. Patients included in the current study are of young age group, due to the existence of chronic inflammation, prolonged use of steroids and the disease prevalence in younger age group. ${ }^{18,20,21}$ The VA improved in half the study group (almost $58 \%$ ), mostly by 2 lines. Our results are less than those reported by Quek et al. ${ }^{11}$ (82\%), and Ganesh et al. ${ }^{10}(80 \%)$. However, our group included patients with combined vision threatening complications of $\mathrm{VKH}$, mainly glaucomatous disc damage and retinal pathologies associated with VKH including subretinal neovascular membranes and fibrosis and macular edema, accounting for poor vision 
in almost one third of eyes after phacoemulsification ${ }^{11,20}$. In a meta-analysis done by Mehta et al. ${ }^{22}$, patients with posterior uveitis such as VKS were found to have poorer visual results than those with other uveitis entities due to chorioretinal injury. However, such eyes may have visual improvement, even if not to $20 / 40$ or better.

The mean time to phacoemulsification was around 3 years, which favors bleb survival. All eyes were at quiescent stage before phacoemulsification by 3 months. Only 2 eyes in the control group developed recurrence of anterior chamber inflammation but none in the study group. Three months of quiescence stage, the better understanding and control of inflammation and the close follow-up are important contributing factors for the prevention of recurrence of inflammation. Phacoemulsification less than one year after trabeculectomy can affect trabeculectomy function. ${ }^{23,24}$ Although there was no significant difference in the trabeculectomy survival rate between both groups, eyes that underwent phacoemulsification required more medications to control the IOP than the control eyes. Phacoemulsification increases blood-aqueous barrier permeability and induces an inflammatory response. The filtration of inflammatory mediators through trabeculectomy flap results in macrophage and fibroblast activation, aggregation, collagen synthesis and deposition and eventual scarring. Furthermore, an increased uveoscleral outflow results in less aqueous drainage through filtering bleb and a high IOP. ${ }^{15}$ The presence of such low-grade inflammation and enriching the bleb area by inflammatory cells can affect trabeculectomy function, increase the IOP and therefore, require more medications.

Differences in the trabeculectomy success rates between the study and control groups were observed during the first 24 months after phacoemulsification. In their study of eyes after cataract surgery, Ehrnrooth et al. reported lower success rates and higher failure after a mean follow-up of 25.3 months compared with our study group ${ }^{19}$. Inal et al. reported no difference in the percentage of eyes considered an absolute success, qualified success and failure between eyes that underwent phacoemulsification and control eyes after 26 months follow-up ${ }^{25}$. Nishizawa et al. reported poor prognosis of IOP control after post-trabeculectomy phacoemulsification in uveitic glaucoma ${ }^{20}$. The current study revealed less IOP control after phacoemulsification in VKH, which is in line with our previous study. Such differences in IOP control can be attributed to the underlying glaucoma and uveitis entities, and the difference in follow-up period, which can be influenced by the natural course of trabeculectomy. The progressive reduction in the cumulative probability of overall success for both groups is most likely due to the natural course of trabeculectomy, the presence of low-grade inflammation related to uveitis, and is consistent with our previous report. ${ }^{15}$

This study has some limitations which include retrospective design, small sample sizes and offers an intermediate-term follow-up result. Collected data were limited to what were available in medical records. However, it represents the first study to evaluate the outcome of phacoemulsification after trabeculectomy in VKH patients. In conclusion, phacoemulsification resulted in higher number of medications to maintain a controlled IOP in glaucomatous VKH eyes. Such change in IOP control did not affect the overall survival. Visual outcome after phacoemulsification is governed by the severity of pre- 
existing glaucoma and retina related complications. Therefore, counselling the patient about such potential outcomes is advisable.

\section{Declarations}

Meeting Presentations: Not presented at any meeting.

Acknowledgment: None.

Financial or Proprietary Interests: None.

Financial Support: None.

Address for correspondence and reprints: Faisal A. Almobarak, Department of Ophthalmology, College of medicine, King Saud University, P.O. Box 245, Riyadh 11411, Saudi Arabia. Tel: +966-11-4786100 Extension: 1426 Fax: +966-11-4775731 Email: falmobarak@ksu.edu.sa

\section{References}

1. Gocho K, Kondo I, Yamaki K. Identification of autoreactive T cells in Vogt-Koyanagi-Harada disease. Invest Ophthalmol Vis Sci 2001;42(9):2004-9

2. Moorthy RS, Inomata H, Rao NA. Vogt-Koyanagi-Harada syndrome. Surv Ophthalmol 1995;39(4):26592

3. Yang P, Ren Y, Li B, Fang W, Meng Q, Kijlstra A. Clinical characteristics of Vogt-Koyanagi-Harada syndrome in Chinese patients. Ophthalmology 2007;114(3):606-14 doi:

10.1016/j.ophtha.2006.07.040[published Online First: Epub Date]|.

4. Fang W, Yang P. Vogt-koyanagi-harada syndrome. Curr Eye Res 2008;33(7):517-23 doi: 10.1080/02713680802233968[published Online First: Epub Date]|.

5. Read RW, Rechodouni A, Butani N, Johnston R, LaBree LD, Smith RE, Rao NA. Complications and prognostic factors in Vogt-Koyanagi-Harada disease. Am J Ophthalmol 2001;131(5):599-606

6. Rubsamen PE, Gass JD. Vogt-Koyanagi-Harada syndrome. Clinical course, therapy, and long-term visual outcome. Arch Ophthalmol 1991;109(5):682-7

7. Abu El-Asrar AM, Al Tamimi M, Hemachandran S, Al-Mezaine HS, Al-Muammar A, Kangave D. Prognostic factors for clinical outcomes in patients with Vogt-Koyanagi-Harada disease treated with high-dose corticosteroids. Acta Ophthalmol 2013;91(6):e486-93 doi: 10.1111/aos.12127[published Online First: Epub Date]|.

8. Arevalo JF, Lasave AF, Gupta V, Arevalo JF, Lasave AF, Gupta V, Kozak I, Al Harbi MB, Al Rushood AA, Al Dhibi HA. Clinical Outcomes of Patients with Vogt-Koyanagi-Harada Disease Over 12 Years at a Tertiary Center. Ocul Immunol Inflamm 2016;24(5):521-9 doi: 10.3109/09273948.2015.1025984[published Online First: Epub Date]|. 
9. Moorthy RS, Rajeev B, Smith RE, Rao NA. Incidence and management of cataracts in Vogt-KoyanagiHarada syndrome. Am J Ophthalmol 1994;118(2):197-204

10. Ganesh SK, Padmaja, Babu K, Biswas J. Cataract surgery in patients with Vogt-Koyanagi-Harada syndrome. J Cataract Refract Surg 2004;30(1):95-100 doi: 10.1016/S0886-3350(03)005522[published Online First: Epub Date]|.

11. Quek DT, Jap A, Chee SP. Risk factors for poor visual outcome following cataract surgery in VogtKoyanagi-Harada disease. Br J Ophthalmol 2011;95(11):1542-6 doi:

10.1136/bjo.2010.184796[published Online First: Epub Date]|.

12. Sung VC, Barton K. Management of inflammatory glaucomas. Curr Opin Ophthalmol 2004;15(2):13640

13. Investigators A. The Advanced Glaucoma Intervention Study: 8. Risk of cataract formation after trabeculectomy. Arch Ophthalmol 2001;119(12):1771-9

14. Read RW, Holland GN, Rao NA, Tabbara KF, Ohno S, Arellanes-Garcia L, Pivetti-Pezzi P, Tessler HH, Usui M. Revised diagnostic criteria for Vogt-Koyanagi-Harada disease: report of an international committee on nomenclature. Am J Ophthalmol 2001;131(5):647-52

15. Almobarak FA, Alharbi AH, Morales J, Aljadaan I. The Influence of Phacoemulsification on Intraocular Pressure Control and Trabeculectomy Survival in Uveitic Glaucoma. J Glaucoma 2017;26(5):444-49 doi: 10.1097/IJG.0000000000000646[published Online First: Epub Date]|.

16. Jabs DA, Nussenblatt RB, Rosenbaum JT, Standardization of Uveitis Nomenclature Working G. Standardization of uveitis nomenclature for reporting clinical data. Results of the First International Workshop. Am J Ophthalmol 2005;140(3):509-16 doi: 10.1016/j.ajo.2005.03.057[published Online First: Epub Date]|.

17. Al-Kharashi AS, Aldibhi H, Al-Fraykh H, Kangave D, Abu El-Asrar AM. Prognostic factors in VogtKoyanagi-Harada disease. Int Ophthalmol 2007;27(2-3):201-10 doi: 10.1007/s10792-007-90629[published Online First: Epub Date]|.

18. Al-Mezaine HS, Kangave D, Abu El-Asrar AM. Patterns of uveitis in patients admitted to a University Hospital in Riyadh, Saudi Arabia. Ocul Immunol Inflamm 2010;18(6):424-31 doi: 10.3109/09273948.2010.502284[published Online First: Epub Date]|.

19. Ehrnrooth P, Lehto I, Puska P, Laatikainen L. Phacoemulsification in trabeculectomized eyes. Acta Ophthalmol Scand 2005;83(5):561-6 doi: 10.1111/j.1600-0420.2005.00499.x[published Online First: Epub Date]|.

20. Jancevski M, Foster CS. Cataracts and uveitis. Curr Opin Ophthalmol 2010;21(1):10-4 doi: 10.1097/ICU.0b013e328332f575[published Online First: Epub Date]|.

21. Almobarak FA, Alharbi AH, Morales J, Aljadaan I. Outcomes of Trabeculectomy With Mitomycin-C in Uveitis Associated With Vogt-Koyanagi-Harada Disease. J Glaucoma 2016;25(6):528-32 doi: 10.1097/IJG.0000000000000384[published Online First: Epub Date]|.

22. Mehta S, Linton MM, Kempen JH. Outcomes of cataract surgery in patients with uveitis: a systematic review and meta-analysis. Am J Ophthalmol 2014;158(4):676-92 e7 doi: 
10.1016/j.ajo.2014.06.018[published Online First: Epub Date]|.

23. Chen PP, Weaver YK, Budenz DL, Feuer WJ, Parrish RK, 2nd. Trabeculectomy function after cataract extraction. Ophthalmology 1998;105(10):1928-35 doi: 10.1016/S0161-6420(98)91044-2[published Online First: Epub Date]|.

24. Nishizawa A, Inoue T, Ohira S, Takahashi E, Saruwatari J, Iwao K, Tanihara H. The Influence of Phacoemulsification on Surgical Outcomes of Trabeculectomy with Mitomycin-C for Uveitic Glaucoma. PLoS One 2016;11(3):e0151947 doi: 10.1371/journal.pone.0151947[published Online First: Epub Date]|.

25. Inal A, Bayraktar S, Inal B, Bayraktar Z, Yilmaz OF. Intraocular pressure control after clear corneal phacoemulsification in eyes with previous trabeculectomy: a controlled study. Acta Ophthalmol Scand 2005;83(5):554-60 doi: 10.1111/j.1600-0420.2005.00497.x[published Online First: Epub Date]|.

\section{Figures}




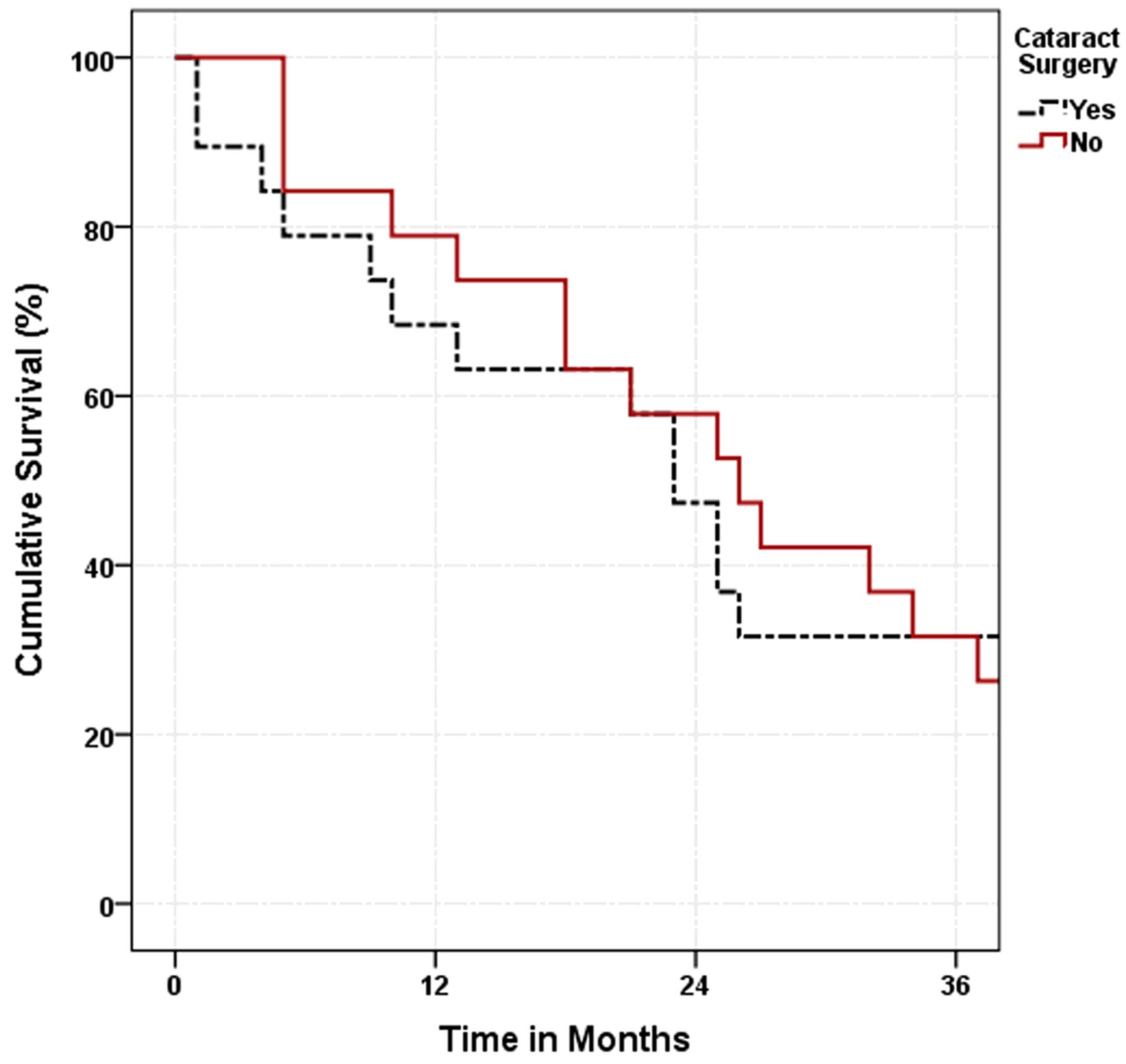

Figure 1

Kaplan-Meier survival curves showing the cumulative probability of success. 